\title{
A Comparative Study of Intrathecal Dexmedetomidine and Fentanyl as an Adjuvant to Bupivacaine (Research Article)
}

\author{
Authors \\ Dr Rashmi Bengali ${ }^{1}$, Dr Tushar Patil ${ }^{2}$, Dr Priya Buddhadeo ${ }^{3}$ \\ ${ }^{1}$ Associate Professor, ${ }^{2}$ Prof \& Head of Department, ${ }^{3}$ Resident
}

Dept of Anaesthesiology, Govt Medical College and Hospital, Aurangabad, 431001 Maharashtra (India)

Corresponding Author

Dr Rashmi Bengali

C-19 Town Centre, Behind Cidco Bus Stand, CIDCO, Aurangabad

Email---drrvbengali@gmail.com, Mobile no.9822441318

\begin{abstract}
In recent years, the use of intrathecal adjuvants has gained popularity. The quality of spinal anaesthesia is improved with addition of opioids and other drugs but no drug is without side effects. The aim of this study was to compare the addition of either Dexmedetomidine or Fentanyl to intrathecal Bupivacaine as regards the onset and duration of sensory and motor block, hemodynamic effects, postoperative analgesia and adverse effects of either drug.

Sixty patients with ASA grade I and II scheduled for lower limb and lower abdominal surgeries were randomly allocated to two groups (30 patients each): Group D received $2.5 \mathrm{ml} 0.5 \%$ hyperbaric Bupivacaine and $5 \mu \mathrm{g}$ of Dexmedetomidine intrathecally. Group F received $2.5 \mathrm{ml} 0.5 \%$ hyperbaric Bupivacaine and $25 \mu \mathrm{g}$ of Fentanyl intrathecally.

Patients in group $F$ had faster onset of motor and sensory block than group $D(P=0.000)$. Patients in group $D$ had significantly longer duration of motor and sensory blockade as compared to those in group $F(P=$ 0.000). Postoperative analgesia was significantly longer in group $D$ than group $F(P=0.000)$. Incidence of side effects among the two groups was not statistically significant.

Fentanyl has faster onset compared with Dexmedetomidine but prolonged duration of sensory and motor blockade with postoperative analgesia was seen with Dexmedetomidine without significant side effects.

Keywords: Dexmedetomidine, Fentanyl, Spinal Anaesthesia, Postoperative analgesia.
\end{abstract}

\section{Introduction}

Regional anaesthesia has emerged as an important technique with simplicity, effectiveness, reliability and safety. It possesses less risk of pulmonary aspiration with excellent muscle relaxation. Additional benefits include reduction in metabolic response to surgery, reduction in blood loss, decreased incidence of thromboembolism, decreased pulmonary compromise (particularly in patients with advanced pulmonary disease) and ability to monitor patient's mental status. Due to short duration of action of local anaesthetics and need for extending the analgesia in postoperative period necessitated the introduction of adjuvants like Midazolam, Neostigmine, Ketamine, Magnesium sulfate, Opioids, $\propto 2$ agonists etc ${ }^{(1)}$. 
Dexmedetomidine is a selective $\alpha 2$-adrenergic receptor agonist. It prolongs analgesia when used intrathecally with local anaesthetics ${ }^{(2)}$. Analgesic action of $\alpha 2$ - adrenergic receptor agonists is a result of depression of the release of presynaptic $\mathrm{C}$-fibre transmitters and by hyperpolarisation of postsynaptic dorsal horn neurons ${ }^{(3)}$. It decreases central nervous system (CNS) sympathetic outflow in a dose dependent manner and has analgesic effects best described as opioid-sparing. Its organ protective effect against ischemic and hypoxic injury makes it cardioprotective, neuroprotective and renoprotective ${ }^{(4)}$

Neuraxial administration of opioids along with local anaesthetics improves the quality of intraoperative analgesia and also provides postoperative pain relief for longer duration. Intrathecally Fentanyl, has rapid onset of action being lipophilic opioid,. It does not tend to migrate to the fourth ventricle in sufficient concentration to cause delayed respiratory depression. It provides better intraoperative analgesia and a safer alternative than morphine for management of early postoperative pain ${ }^{(5)}$. The capacity of spinal opiates to reduce the release of excitatory neurotransmitter from $\mathrm{C}$ fibers and decrease the excitability of dorsal horn neuron accounts them for the powerful and selective on spinal nociceptive processing.

\section{Material and methods}

After the approval of the ethical committee, written informed consent was obtained from all patients. Inclusion criterias were -patients between 18 and 50 years of age of either sex, height more than $150 \mathrm{~cm}$, (ASA) physical status I and II and patients scheduled for elective lower abdominal or lower limb surgeries. Exclusion criterias werepregnancy and lactation, allergy to the study medications, heart block and dysrrhythmias, hypertension, therapy with adrenergic receptor antagonist, calcium channel blocker, and/or angiotensin converting enzyme inhibitor, and patients with contraindications for spinal anaesthesia. After detail history, complete physical examination and laboratory investigations were carried out. Standard monitors with -ECG, noninvasive arterial blood pressure, and oxygen saturation were applied. Patients were preloaded with intravenous lactated Ringer's solution $10 \mathrm{ml} / \mathrm{kg}$. Spinal anaesthesia was induced in the sitting position at the L3-L4 interspace using a 25 G Quincke's spinal needle with all aseptic precautions.

\section{Study Design:}

Prospective, Randomized, Double blind study

\section{Group D}

Inj Bupivacaine 0.5\% (H) $2.5 \mathrm{cc}$ (12.5mg)

+ Inj Dexmedetomidine $5 \mu \mathrm{g}$ in $0.5 \mathrm{ml} \mathrm{NS}$ [Total volume $3 \mathrm{cc}$ ]

\section{Group F}

- Inj Bupivacaine 0.5\% (H) 2.5 cc (12.5mg) + Inj Fentanyl $25 \mu \mathrm{g}$ [Total volume 3cc]

Injection was given over $10-15 \mathrm{sec}$; immediately patients were made to lie supine. All patients were given 4 lit/ min supplemental oxygen with face mask.

Pulse rate and blood pressure were monitored immediately after injection and then every $2 \mathrm{~min}$ till $10 \mathrm{~min}$ and every $5 \mathrm{~min}$ for $30 \mathrm{~min}$ and then every $15 \mathrm{~min}$ thereafter till the end of surgery and till the recovery from block. Thereafter every 2 hours till 24 hours. Hypotension was defined as decrease in systolic blood pressure by more than $30 \%$ from baseline, treated with IV fluids and 3 mg Mephenteramine IV. Bradycardia was defined as a heart rate less than 50 beats per minute treated with $0.6 \mathrm{mg}$ of Atropine IV. The incidence of adverse effects such as hypotension, bradycardia, nausea, vomiting, shivering, pruritus, respiratory depression was recorded.

Sedation: was assessed with the Ramsay Sedation Score:

Score- (1) Anxious, restless or both.

(2) Cooperative, oriented and tranquil.

(3) Responding to commands.

(4) Brisk response to glabellar tap.

(5) Sluggish response to glabellar tap. 


\section{(6) No response.}

\section{Sensory Block Assessment:}

Sensory level was determined by pinprick using $24 \mathrm{G}$ hypodermic needle. Onset of sensory level was defined as time interval from completion of subarachnoid injection i.e. zero time to loss of pinprick sensation at umbilicus (T10). Maximum sensory level was tested in midclavicular line every minute until the level is stabilized for two consecutive tests. Afterwards sensory level was tested every 15 min until two segment regression for duration of anaesthesia. Time taken to achieve maximum sensory level and 2 segment regression was noted.

Postoperatively patients were interrogated every 15 min for pain at surgical site. Analgesics were not given until demanded by patient. Time taken from administration of drug to time patient first demanded analgesic was noted which is considered as duration of effective analgesia.

\section{Motor Block Assessment:}

It was assessed by straight leg raising while lying supine and was graded according to modified Bromage scale ${ }^{(6)}$.

Grade 0 - no motor block

Grade 1 - inability to raise extended leg

Grade 2 - inability to flex knee but able to

flex ankle

Grade 3 - inability to flex ankle complete motor block

Onset of motor block was defined as time taken from injection of drug till patient was unable to flex ankles.

Recovery of motor block was defined as ability of patient to flex hip and was recorded every $15 \mathrm{~min}$. Duration of motor block was calculated from 0 time up to recovery of motor block.

\section{Postoperative Pain Assessment:}

Duration of postoperative analgesia was measured from the time of injection of spinal anaesthesia to the time when pain score becomes more than or equal to 3 according to VAS. Then patient was given Inj Diclofenac Sodium 75mg IV.

VAS score:

No pain

1, 2, 3- mild pain

$4,5,6$ - moderate pain

7, 8, 9 - severe pain

-worst pain

\section{Data Analysis:}

Quantitative data is presented with the help of Mean, Standard deviation; comparison among study group was done with the help of Unpaired $\mathrm{T}$ test or Mann-Whitney test as per results of Normality test. Qualitative data is presented with Frequency and Percentage tables; association among study parameters is assessed with the help of Chi-Square test (Fisher Exact test for $2 \times 2$ tables). $\mathrm{P}$ value less than 0.05 is taken as significant.

\section{Observations and results:}

In our observations Group D denotes patients receiving $12.5 \mathrm{mg} 0.5 \%$ Bupivacaine with $5 \mu \mathrm{g}$ Dexmedetomidine and Group F denotes patients receiving $12.5 \mathrm{mg} 0.5 \%$ Bupivacaine with $25 \mu \mathrm{g}$ Fentanyl.

The groups were comparable with respect to age, height, weight and sex (Table 1 and 2)

The onset was significantly faster in group $\mathrm{F}$ $(369.33 \pm 41.27 \mathrm{sec})$ compared with group D $(462 \pm 61.33 \mathrm{sec})$. In group $\mathrm{D}$, the mean time to reach highest sensory level was $10.65 \pm 1.73 \mathrm{~min}$; in group $\mathrm{F}$ it was $7.92 \pm 0.64 \mathrm{~min}$. Group D $(138.83 \pm 11.5 \mathrm{~min})$ had significantly longer duration of sensory block as compared with groups $\mathrm{F}(115.5 \pm 9.94 \mathrm{~min})$. The onset of motor block in group F $(472 \pm 49.16 \mathrm{sec})$ was significantly faster compared with group D $(540 \pm 66.85 \mathrm{sec})$. The regression time to modified Bromage score 0 was slower in group D compared with group F; with a total mean duration of motor block in group D was $301.67 \pm 19.45 \mathrm{~min}$; in group $\mathrm{F}$ was $267.50 \pm 11.2 \mathrm{~min}$. 
The time to first analgesia request was significantly longer in group D (344.67 \pm 25.43 $\mathrm{min})$ compared with group $\mathrm{F}(240.83 \pm 24 \mathrm{~min})(P$ $=0.000)$. (Table no. 3 )
There were no significant complications on comparing the two groups (Table no. 4)

Table No.1 Comparison of Demographic Characteristics Including Age, Height and Weight

\begin{tabular}{|l|l|l|l|}
\hline Study parameter & Group D & Group F & P value \\
\hline Age $(\mathrm{yrs})$ & $33.6 \pm 9.74$ & $31.7 \pm 9.01$ & $0.436(\mathrm{NS})$ \\
\hline Weight $(\mathrm{kg})$ & $64.4 \pm 6.25$ & $63.77 \pm 6.58$ & $0.617(\mathrm{NS})$ \\
\hline Height $(\mathrm{cm})$ & $161.5 \pm 6.42$ & $159.73 \pm 6.34$ & $0.288(\mathrm{NS})$ \\
\hline
\end{tabular}

( $\mathrm{T}$ Test applied, $\mathrm{p}$ value is significant if <0.05) Values are represented as mean $\pm \mathrm{SD}$

Table No. 2 Comparison of Demographic Characteristics Including Gender

\begin{tabular}{|l|l|l|l|}
\hline & Group D & Group F & P value \\
\hline Male & 24 & 21 & \multirow{3}{*}{$0.371(\mathrm{NS})$} \\
\hline Female & 6 & 9 & \\
\hline Total & 30 & 30 & \\
\hline
\end{tabular}

( $\mathrm{T}$ Test applied, $\mathrm{p}$ value is significant if $<0.05$ ) $\quad$ Values are represented as mean \pm SD

Table No. 3 Comparison of Study Group For

\begin{tabular}{|l|l|l|l|}
\hline Study parameter & Group D & Group F & P Value \\
\hline Onset of sensory block(sec) & $462 \pm 61.33$ & $369.33 \pm 41.27$ & 0 (significant) \\
\hline Time to cephalic spread(min) & $10.65 \pm 1.73$ & $7.92 \pm 0.64$ & 0 (significant) \\
\hline Two segment regression(min) & $138.83 \pm 11.5$ & $115.5 \pm 9.94$ & 0 (significant) \\
\hline Onset of motor block(sec) & $540 \pm 66.85$ & $472 \pm 49.16$ & 0 (significant) \\
\hline Duration of motor block(min) & $301.67 \pm 19.45$ & $267.50 \pm 11.2$ & 0 (significant) \\
\hline Duration of surgery $(\min )$ & $101.17 \pm 11.72$ & $98.33 \pm 13.41$ & 0.387 (Not significant) \\
\hline Post operative analgesia(min) & $344.67 \pm 25.43$ & $240.83 \pm 24$ & 0 (significant) \\
\hline
\end{tabular}

( $\mathrm{T}$ Test applied, $\mathrm{p}$ value is significant if $<0.05$ ) Values are represented as mean \pm SD

Table No 4 Comparison of Overall Incidence of Side Effects and Complications

\begin{tabular}{|l|c|c|c|}
\hline Complication & Group D & Group F & Total \\
\hline Bradycardia & $4(13.3 \%)$ & $1(3.3 \%)$ & $5(8.3 \%)$ \\
\hline Hypotension & $3(10 \%)$ & $2(6.7 \%)$ & $5(8.3 \%)$ \\
\hline Nausea and vomiting & $1(3.3 \%)$ & $2(6.7 \%)$ & $3(5 \%)$ \\
\hline Pruritus & $0(0.0 \%)$ & $2(6.7 \%)$ & $2(3.3 \%)$ \\
\hline Shivering & $0(0.0 \%)$ & $2(6.7 \%)$ & $2(3.3 \%)$ \\
\hline No complication & $22(73.3 \%)$ & $21(70 \%)$ & $43(71.7 \%)$ \\
\hline Total & $30(100 \%)$ & $30(100 \%)$ & $60(100 \%)$ \\
\hline
\end{tabular}

$\left(\mathrm{X}^{2}=6.357, \mathrm{~d}(\mathrm{f})=5, \mathrm{p}\right.$ value- 0.273 (not significant)

(Chi square test is applied. $\mathrm{P}$ value is significant if $<0.005$ ) 
Discussion

Nature has placed mankind under the government of two sovereign masters - PAIN AND PLEASURE

\section{JEREMY BENTHAM (1748-1832)}

The sole essence of anaesthesia is pain relief in perioperative period for which spinal anaesthesia is the most commonly used technique. However, for postoperative pain control, spinal anaesthesia using only local anaesthetics is associated with relatively short duration of action, and thus early analgesic intervention is needed ${ }^{(7)}$.

The quality of the spinal anaesthesia is improved by the addition of opioids (such as Morphine, Fentanyl and Sufentanil) and other drugs such as Dexmedetomidine, Clonidine, Magnesium sulphate, Neostigmine, Ketamine and Midazolam, but no drug to inhibit nociception is without associated adverse effects. ${ }^{(1)}$

Fentanyl is a lipophilic mu receptor agonist opioid. Intrathecally, Fentanyl exerts its effect by combining with opioid receptors in the dorsal horn of the spinal cord and may have a supraspinal spread and can exhibit various adverse actions ${ }^{(8)}$. Sullivan et $a l^{(9)}$ have studied the ED50 of $2.5 \mu \mathrm{g}$ Dexmedetomidine for inhibition of $\mathrm{C}$ fibre responses of dorsal horn neurons and $A \beta$-evoked responses were inhibited to a lesser degree with a maximum inhibition seen above $10 \mu \mathrm{g}$ dose.

$\propto$ 2adrenoreceptor agonists act by binding to the presynaptic C-fibers and postsynaptic dorsal horn neurons. They produce analgesia by depressing the release of $\mathrm{C}$-fiber transmitters and by hyperpolarization of post synaptic dorsal horn neurons. The complementary action of local anaesthetics and $\propto 2$ adrenoreceptor agonists account for their profound analgesic properties. The prolongation of the motor block of spinal anaesthetics may be the result of binding of $\propto 2$ adrenoreceptor agonists to the motor neurons in the dorsal horn. Dexmedetomidine is eight times more specific and highly selective $\propto 2$ adrenoreceptor agonists compared to Clonidine, thereby making it a useful and safe adjunct in diverse clinical applications ${ }^{(10)}$. In a few dose finding studies, investigators have used 3, 5, and $10 \mathrm{mcg}$ of intrathecal Dexmedetomidine in human subjects with favorable results, ${ }^{(13),(14),(15)}$ along with preserved hemodynamic stability and lack of sedation.

In our study, the distribution of patients according to age, gender, height and weight was comparable and statistically insignificant $(\mathrm{p}>0.05)$. (Table no. $1,2)$

Onset of sensory block was significantly longer $(\mathrm{p}<0.001)$ in group D $(462 \pm 61.33 \mathrm{sec})$ as compared to group F $(369.33 \pm 41.27 \mathrm{sec})$. (Table no.3)

The mean time to achieve maximum sensory block in group $\mathrm{D}(10.65 \pm 1.73 \mathrm{~min})$ and in group $\mathrm{F}$ (7.92 $\pm 0.64 \mathrm{~min})$. (Table no.3)

Similar maximum sensory dermatomal level was achieved by Dexmedetomidine and Fentanyl in equipotent doses.

The mean time to achieve onset of motor block in group D $(540 \pm 66.85 \mathrm{sec})$ was significantly higher (P value 0.000$)$ than group $F(472 \pm 49.16 \mathrm{sec})$. (Table no.3)

The reason for the observed difference between our results and that seen in the other studies could be attributed to the methodological differences like difference in the drug dosage and baricity or total volume of drug used.

Mean time required for two segment regression was significantly higher ( $\mathrm{P}$ value -0.000 ) in group D $(139.83 \pm 11.5 \mathrm{~min})$ than group $\mathrm{F}$ (115.5 $\pm 9.94 \mathrm{~min})$. (Table no.3)

Mean duration of motor block was significantly higher in group D $(301.67 \pm 19.45 \mathrm{~min})$ as compared to group F $(267.50 \pm 11.2 \mathrm{~min})$ (Table no.3)

Duration of postoperative analgesia was significantly longer in group D (344.67 $\pm 25.43 \mathrm{~min})$ as compared with group $\mathrm{F}$ (240.83 $\pm 24 \mathrm{~min})$. (Table no.3)

Thus Dexmedetomidine prolongs the duration of sensory block, and also the duration of the motor block. Dexmedetomidine acts on $\propto 2$ adrenoreceptors in substantia gelatinosa of spinal 
cord and blocks $\mathrm{C}$ and $\mathrm{A}$ delta fibers, it increases the potassium conductance intensing the conduction block of local anaesthetics. It may have an additive or synergistic effect with local anaesthetic in increasing the time of two segment regression and total duration of complete analgesia. The potentiation of motor block by Dexmedetomidine may be an additive or synergistic effect to the local anaesthetics or related to the interference with neuromuscular activity or binding of $\alpha 2$-agonists to motor neurons in the dorsal horn ${ }^{(16)}$.

Dexmedetomidine produce sedative effect by acting on $\propto 2$-adrenergic receptors in locus ceruleus.

In our study the mean sedation scores were found to be comparable and statistically insignificant $(\mathrm{p}>0.05)$ preoperatively and intraoperatively among the two groups.

Preoperatively and intraoperatively the difference between mean PR, SBP, DBP, MAP, RR, $\mathrm{SpO}_{2}$ were insignificant ( $p$ value $>0.005$ )

Intrathecal narcotics, enhance the sensory blockade and prolong postoperative analgesia. They are associated with increased risk of nausea, vomiting, itching and respiratory depression. Opioids are known to depress all phases of respiration by their action on the opioids receptors in the ventral medulla, irrespective of route of administration. Fentanyl is a $\mu$ receptor agonist which can be administered safely intrathecally. It is highly lipophillic which prevents its rostral spread. But, systemic absorption of the drug could contribute to the lower respiratory rates by direct depressant action on $\mu$ receptors in brainstem. Although the incidence of intraoperative and postoperative complications were not statistically significant among the two groups. (Table no.4)

\section{Conclusion}

It can be concluded from the study that Fentanyl has comparably faster onset of sensory and motor blockade than Dexmedetomidine. Prolonged duration of sensory and motor block with excellent quality of anaesthesia was seen with
Dexmedetomidine as compared to Fentanyl. In addition Dexmedetomidine significantly prolongs the duration of postoperative analgesia as compared to Fentanyl without any statistically significant side effects.

\section{References}

1. Deepika Shukla, Anil Verma, Apurva Agarwal et al. Comparative study of intrathecal Dexmedetomidine with intrathecal Magnesium sulphate used as adjuvants to bupivacaine. J Anaesthesiol Clin Pharmacol. 2011; 27(4): 495-499.

2. Sudheesh K, Harsoor SS. Dexmedetomidine in anaesthesia practice: A wonder drug? Indian J Anaesth 2011;55:323-4.

3. Eisenach JC, De Kock M, Klimscha W. alpha (2)-adrenergic agonists for regional anaesthesia. A clinical review of clonidine (1984-1995). Anesthesiology 1996;85 :655-74.

4. Joana Afonso, Flávio Reis Dexmedetomidine: Current Role in Anaesthesia and Intensive Care Revista Brasileira de Anestesiologia Vol. 62, No 1, January- February, 2012

5. Biswas BN, Rudra A, Bose BK, Nath S, Chakrabarty S. Intrathecal Fentanyl with hyperbaric bupivacaine improves analgesia during caesarean delivery and in early postoperative period. Indian $\mathbf{J}$ Anaesth 2002; 46(6): 469-472

6. Bromage PR. A comparison of the hydrochloride and carbon dioxide salts of lidocaine and prilocaine in epidural analgesia. Acta Anaesthesiol Scand Suppl 1965; 16:55-69.

7. Ramila H Jamliya, Varun Deshmukh, Rajesh C, Jyostana Maliwad et al. Effect Of Adding Dexmedetomidine In Intrathecal Bupivacaine Versus Intrathecal Bupivacaine Alone On Spinal Block Characteristics In Orthopaedic Lower 
Limb Procedures [A Comparative Study]. RJPBCS 2013; 4 (1): 1340

8. Ahmed El-Attar, Mohamed Abdel Aleem, Ragab Beltagy, Wafaa Ahmed. A comparative study of intrathecal Dexmedetomidine and Fentanyl as additives to bupivacaine. Research and Opinion in Anaesthesia \& Intensive Care 2015, 1:43-49

9. Sullivan AF, Kalso EA, McQuay HJ, Dickenson AH. The antinociceptive actions of Dexmedetomidine on dorsal horn neuronal responses in the anaesthetized rat. Eur J Pharmacol 1992;215:127-33.

10. Mahendru V, Tewari A, Katyal S, Grewal A, Singh MR, Katyal R. A comparison of intrathecal Dexmedetomidine, Clonidine, and Fentanyl as adjuvants to hyperbaric bupivacaine for lower limb surgery: A double blind controlled study. J Anaesthesiol Clin Pharmacol 2013;29:496502.

11. Rajni Gupta, Reetu Verma, Jaishri Bogra, Monica Kohli, Rajesh Raman, and Jitendra Kumar Kushwaha A Comparative study of intrathecal Dexmedetomidine and Fentanyl as adjuvants to Bupivacaine. $\mathrm{J}$ Anaesthesiol Clin Pharmacol. 2011 JulSep; 27(3): 339-343.

12. Jain A, Jain K, Bhardawaj N. Analgesic efficacy of low-dose intrathecal neostigmine in combination with Fentanyl and bupivacaine for total knee replacement surgery. J Anaesthesiol Clin Pharmacol. 2012; 28(4): 486-90

13. Kanazi GE, Aouad MT, Jabbour- Khoury SI, Al Jazzar MD, Alameddine MM, AlYaman R, et al. Effect of lowdose Dexmedetomidine or clonidine on the characteristics of bupivacaine spinal block. Acta Anesthesiol Scand 2006;50:222-7.
14. Al Mustafa MM, Abu Halaweh SA, Aloweidi AK, Murshidi MM, Ammari BA, Awwad ZM, et al. Effect of Dexmedetomidine added to spinal bupivacaine for urological procedures. Saudi Med J 2009;30:365-70.

15. Al-Ghanem SM, Massad IM, Al-Mustafa MA, Al-Zaben KR, Qudaisat IY, Qatawneh AM, et al. Abu-Ali. Effect of Adding Dexmedetomidine versus Fentanyl to Intrathecal Bupivacaine on Spinal Block Characteristics in Gynecological Procedures: A Double Blind Controlled Study. Am J Applied Sci 2009;6:882-7.

16. Ji Eun Kim,Na Young Kim,Hye Sun Lee and Hae Keum Kil. Effects of Intrathecal Dexmedetomidine on Low-Dose Bupivacaine Spinal Anaesthesia in Elderly Patients Undergoing Transurethral Prostatectomy. Biol. Pharm. Bull. 36(6) 959-965 (2013)

17. Grewal A. Dexmedetomidine: New avenues. J Anaesthesiol Clin Pharmacol 2011;27:297-302

18. Saxena A, Arava S. Current concepts in neuraxial administration of opioids and non-opioids: An overview and future perspectives. Indian Journal of Anaesthesia 2004; 488(1): 13-24. 